\title{
Analyzing Opinions and Argumentation in News Editorials and Op-Eds
}

\author{
Bal Krishna Bal \\ Information and Language Processing Research Lab \\ Department of Computer Science and Engineering \\ Kathmandu University, P.O. Box - 6250 \\ Dhulikhel, Kavre, Nepal
}

\begin{abstract}
Analyzing opinions and arguments in news editorials and op-eds is an interesting and a challenging task. The challenges lie in multiple levels - the text has to be analyzed in the discourse level (paragraphs and above) and also in the lower levels (sentence, phrase and word levels). The abundance of implicit opinions involving sarcasm, irony and biases adds further complexity to the task. The available methods and techniques on sentiment analysis and opinion mining are still much focused in the lower levels, i.e., up to the sentence level. However, the given task requires the application of the concepts from a number of closely related sub-disciplines - Sentiment Analysis, Argumentation Theory, Discourse Analysis, Computational Linguistics, Logic and Reasoning etc. The primary argument of this paper is that partial solutions to the problem can be achieved by developing linguistic resources and using them for automatically annotating the texts for opinions and arguments. This paper discusses the ongoing efforts in the development of linguistic resources for annotating opinionated texts, which are useful in the analysis of opinions and arguments in news editorials and op-eds.
\end{abstract}

Keywords-editorials; opinions; arguments; persuasion; sentiment analysis; annotation; NLP

\section{INTRODUCTION}

News editorials and op-eds, which fall under particular kinds of persuasive texts, are rich sources for discourse analysis on particular events. However, in the context of the growing number of news editorials both in the print and online media, such an analysis becomes difficult owing to at least two reasons - the first one being the enormous amount of content to handle and the other one being the challenge to decide on the relative biases and objectivity of the editorial texts. Since editorials are necessarily views and opinions of the news agencies or the columnist involved, it is often the case that all possible measures of persuasion are employed lest the text sounded convincing or persuading. It is quite a common phenomenon in such texts to come across opinions seemingly to be facts (opinions in disguise of facts), rhetoric, exaggerations, sarcasm and irony.

Given a computational perspective to address the above task, there is clearly a need to analyze the texts in different levels - the discourse level (paragraph level or above), the sentence level, phrase level and the word level.This encompasses the application of the concepts from a number of closely related disciplines like Sentiment Analysis, Argumentation Theory, Discourse Analysis, Computational
Linguistics, Logic and Reasoning etc.[1]. Apparently, this is a difficult task for humans, let alone the machine. The primary argument of this paper is that partial solutions to the problem can be achieved by developing linguistic resources and using them for automatically annotating data for opinions and arguments. Such annotated data would be very useful in the analysis of opinions and arguments. This paper discusses the ongoing efforts in the development of linguistic resources for analyzing opinions and arguments in news editorials and opeds.

The paper is organized in altogether seven sections. Section II introduces the underlying argument structure in persuasive texts. Section III talks about the current efforts made by the given research work in building a corpus of editorials and opeds. Section IV explains the semantic tagset developed for annotating the corpus. Section $\mathrm{V}$ gives an overview of the different linguistic resources required for the annotation work. Section VI presents and discusses the results of the annotation work and performance of the automatic annotation tool. Finally, Section VII discusses the conclusion and future extensions to the given research work.

\section{The Underlying Argument Structure IN PERSUASIVE TEXTS}

Persuasive writings in general and particularly editorials of argumentation and persuasion exhibit the following argumentation structure $\mathrm{r}$ :

- Opening or thesis statement

- Support statements (facts/opinions)

- Conclusion

The opening or thesis statement introduces the issue or the problem in consideration while the support statements try to convince the readers on the issue being discussed. The conclusion part usually expresses promise or offers some recommendations to the readers. In most cases, the conclusion repeats the thesis statement with slight rephrasing still intending to convey the same views put forward earlier.

For convincing the readers, the authors of such persuasive texts provide relevant evidences (facts andlor opinions) with examples, make use of logical connectives like 'Firstly',

\footnotetext{
${ }^{1}$ Adapted from the National Literacy Strategy Grammar for Writing p154/5
} 
'Secondly', 'Finally', 'Because', 'Consequently', 'So', 'Therefore' etc. to structure and link the ideas within arguments.

Other persuasive devices that are often used in such texts include information dealing with statistics and numbers (for example, 'More than $80 \% \ldots .$. ), emotive words (for example, strong adjectives and adverbs like 'alarming', 'surely' etc.) and rhetorical questions like 'Are we meant to suffer like this when we have been toiling so hard?'.

Editorials, which align more closely to persuasive texts than argumentation texts are found to adhere closely to the classical definition and structure of argumentation - proposition or thesis statement followed by supports and finally the conclusion [2-4].

\section{BUILDING A CORPus Of EDITORIALS AND Op-EdS}

For studying the structure of editorials, editorials are gathered for the time span 2007 - 2012, from two local English news portals from Nepal, respectively, 'The Kathmandu Post' (http://ekantipur.com/tkp/), 'Nepali Times' (http://nepalitimes.com) and similarly op-eds from three international English news portals, namely, 'BBC' (http://bbc.co.uk), 'Aljazeera' (http://aljazeera.com) and 'The Guardian' (http://guardian.com).

The study shows that the editorials and op-eds from all of the news portals exhibit a more or less similar structure adhering to persuasive texts with the following characteristics:

- Every paragraph has a thesis statement or introduction of an issue, which is elaborated or provided supports further in the paragraph thus confirming that they do follow the structure identified above.

- In terms of discourse, each paragraph represents a separate view point necessarily consolidating the views or providing supports to the topic of the editorial or overall discourse.

- The supporting statements in the paragraph are linked to each other via rhetorical relations and signaled by the logical connectives or discourse cues.

- The overall orientation of the supporting statements (Positive or Negative) can be analyzed by evaluating the opinion words or phrases occurring in the individual statements.

- The strength or the intensity of the opinions expressed in statements can be determined by evaluating the intensifiers or pre-modifiers coming in front of opinions and similarly by judging the presence of report and modal verbs that signal the commitment or intent level of the opinions.

The above findings pinpoint that the development of suitable linguistic resources can prove vital for providing at least partial solutions to the given task. In Table I, the statistics of the downloaded editorials and op-eds are presented.
TABLE I. DOWNLOAD STATISTICS OF EDITORIALS AND OP-EDS

\begin{tabular}{|c|c|}
\hline Source & Downloads (texts files) \\
\hline The Kathmandu Post & 1718 \\
\hline Nepali Times & 211 \\
\hline BBC & 853 \\
\hline Aljazeera & 1830 \\
\hline The Guardian & 6191 \\
\hline
\end{tabular}

\section{Devising A Semantic Tagset For Annotating The} CORPUS

There have been growing efforts in developing annotated resources so that they can be useful in acquiring annotated patterns using statistical or machine learning approaches and ultimately aid in the automatic identification, extraction and analysis of opinions, emotions and sentiments in texts. Some of such works on text annotation, among many others, include [58].These works are primarily focused on annotating opinions or appraisal units (attitude, engagement and graduation) in texts, which share similar notions with the Appraisal Framework developed by [9]. Other works on annotating texts include [10, 11] etc. which deal with text annotation in the discourse level employing discourse connectives and discourse relations. However, despite these efforts, the development of a suitable annotation scheme for corpus annotation from the perspective of opinion and argumentation analysis in opinionated texts seem to be clearly missing. While the existing annotation schemes and guidelines may be sufficient for annotating appraisal units, discourse units and even possibly some rhetorical relations, for analyzing the argumentation structure, it is necessary to determine the type of supports with respect to a statement (either "For" or "Against") and the commitment or intent levels of the opinions and the overall persuasion effects in opinionated texts. This then requires for this research work to make some additional provisions in the annotation scheme which are as follows:

- Introduction of some metadata of the source text like date and source of publication useful for source attribution in opinionated texts.

- Parameters for identifying arguments and for determining the orientation of their supports.

- Attributes for determining the strength of opinions and arguments or commitment level expressed in the form of different modal and report verbs.

- Other forms of expressions indicating persuasion effect of opinions and arguments (mostly involving words or phrases consisting of one or more adjectives, adverbs, intensifiers, pre-modifiers in combination or in isolation).

With the above issues in consideration and after manually analyzing selected opinionated texts from the corpus, a semantic tagset was developed specifically designed for the annotation of the opinionated texts, a sample of the tagset and brief explanation of the tags is provided in Table II below: 
TABLE II. SEMANTIC TAgSET

\begin{tabular}{|c|c|}
\hline Parameters & Possible values/Explanations \\
\hline Topic & The title or topic of the opinionated text \\
\hline Gist & $\begin{array}{l}\text { The summary or abstract of the opinionated text. Usually, this is provided in the form of one or more sentences at } \\
\text { the beginning of each text. }\end{array}$ \\
\hline Author & $\begin{array}{l}\text { The name of the author if available. Generally in editorials, the name of the author is not provided but in case of } \\
\text { op-eds, usually, the names of the author(s) are mentioned. }\end{array}$ \\
\hline URL & The uniform resource locater or the web link to the opinionated text. \\
\hline Date & The date of publication of the opinionated text. \\
\hline Source & The source or the news portal from where the opinionated text is taken from. \\
\hline argument_id & $\begin{array}{l}\text { The argument's identity number. For simplicity, in this annotation scheme, each paragraph is regarded as an } \\
\text { argument. This is because in argumentative text, the basic rule is that a paragraph generally sticks to a particular } \\
\text { idea with several supporting/refuting evidence to the given idea. The numbering of the argument starts from } 0 \text { and } \\
\text { this increases globally in the whole text as the paragraphs advance from top to bottom. }\end{array}$ \\
\hline statement_id & $\begin{array}{l}\text { The statement/sentence number within an argument or paragraph. Each sentence is considered to be a statement. } \\
\text { The numbering of the statement starts from } 0 \text {. The numbering of the statement is relative to each paragraph. }\end{array}$ \\
\hline statement_type & $\begin{array}{l}\text { Can be either a "thesis statement" or "support statement" but not both. Usually, a thesis statement puts forward a } \\
\text { claim or a belief and the support statement supports or refutes the claim. }\end{array}$ \\
\hline support_type & $\begin{array}{l}\text { A statement or sentence can take either of the three values - "For" or "Against" or "Neutral". If the supporting } \\
\text { statement supports the claim, it is said to be providing a positive support or "For" and if the supporting statement } \\
\text { refutes the claim, it is said to be providing a negative support or "Against". Similarly, if the supporting statement } \\
\text { does not support or refute the claim, it is said to be neutral, "Neutral" with respect to the claim. }\end{array}$ \\
\hline exp_type & $\begin{array}{l}\text { A statement or sentence as an expression can take either of the three values - "Opinion", or "Fact" or "Undefined". } \\
\text { A statement is tagged as an opinion if it represents a view, emotion, judgment etc. Similarly, a statement is tagged } \\
\text { as fact if it expresses some factual information. If a statement cannot be tagged as an "Opinion" or a "Fact", it is } \\
\text { tagged as "Undefined". Often, there may be situations whereby a portion of a statement represents a fact while the } \\
\text { other portion is an opinion. However, currently we handle just statements with either factual or opinionated } \\
\text { expressions but not both. }\end{array}$ \\
\hline fact_authority & $\begin{array}{l}\text { If a statement or sentence has been tagged as "Fact", the attribute "fact_authority" can take either "Yes" or "Est." } \\
\text { depending upon whether the fact has an authority to confirm about its authenticity or that it is an established fact. } \\
\text { For well-established facts like "The earth is round" or "The sun rises from the east and sets in the west", the } \\
\text { attribute "fact_authority" takes the value "Est.", meaning "Established". }\end{array}$ \\
\hline opinion_orientation & $\begin{array}{l}\text { If a statement or sentence has been tagged as "Opinion", the attribute "opinion_orientation" can take either of the } \\
\text { three values -"Positive", "Negative" or "Neutral". There can be one or multiple opinion terms of different polarity } \\
\text { or orientation in a statement but the statement has to be tagged taking into consideration the overall effect in terms } \\
\text { of opinion orientation. If the statement does not bear any particular opinion orientation, i.e., either "Positive" or } \\
\text { "Negative", it is tagged as "Neutral". }\end{array}$ \\
\hline opinion_strength & $\begin{array}{l}\text { This attribute tags a statement or sentence for the overall opinion strength across seven extended scale parameters - } \\
\text { "Lowest" or "Lower" or "Low" or "Average" or "High" or "Higher" or "Highest". The general basic strength } \\
\text { categories are however, "Low", "Average" and "High" with the other four grades resulting when one or more } \\
\text { intensifiers or pre-modifiers come in front of the three basic strength categories. A statement can have multiple } \\
\text { opinion terms of varying strengths but the overall opinion strength has to be considered. }\end{array}$ \\
\hline persuasion_effect & $\begin{array}{l}\text { This attribute tags a statement or sentence with one of the values - "Yes" or "No". If the sentence or statement has } \\
\text { an overall persuasion effect or is of convincing nature, the attribute "persuasion_effect" takes the value "Yes", } \\
\text { otherwise, it takes a "No" value. }\end{array}$ \\
\hline Conditional & $\begin{array}{l}\text { This attribute tags a sentence or statement with one of the values "Yes" or "No". If the statement is of conditional } \\
\text { nature, the attribute "conditional" takes the value "Yes", otherwise, it takes a "No" value. }\end{array}$ \\
\hline commitment_level & $\begin{array}{l}\text { This attribute tags a statement or sentence with one of the values - "Low", "Average" or "High". The major } \\
\text { decision to tag the sentences with one of the above values is determined by the presence of different modal and lor } \\
\text { reporting verbs of varying commitment or intent levels. }\end{array}$ \\
\hline
\end{tabular}




\begin{tabular}{|l|l|}
\hline rhetorical_relation_type & $\begin{array}{l}\text { This attribute tags the support statement or sentence with one of the following values - "Exemplification", } \\
\text { "Contrast", "Justification", "Elaboration", "Paraphrase", "Cause-Effect", "Result", "Explanation", } \\
\text { "Reinforcement" and "Conditional". The tagging for the given attribute is based on explicit or implicit discourse } \\
\text { markers or connectives present in the support statement with respect to the thesis statement or in between the } \\
\text { preceding or following support statements with respect to the current support statement. }\end{array}$ \\
\hline
\end{tabular}

\section{Development Of Linguistic Resources}

For annotating the editorials and op-ed texts from the corpus with opinion and argument attributes as mentioned in the semantic tagset, some linguistic resources were developed within this research work, which is described in the following sections.

\section{A. Sentiment/Polarity Lexicon}

Sentiment/Polarity Lexicon represents as a valuable resource for determining the orientation or polarity of opinions in opinionated texts, particularly in the word, phrase and sentence levels. A few of such lexicons already exist for the English language, for example, the opinion lexicon developed by $[12,13]$, subjectivity clues developed by $[14,15]$, SentiWordNet developed by [16]. However, it should be noted that these lexicons in themselves do not serve as exhaustive lists as new opinion terms keep on coming up quite often over time with new domains. For the given task of analyzing opinions and arguments in opinionated tasks, the opinion lexicon for English by [12] is taken as a baseline resource, which consists of 2041 positive terms and 4818 negative terms. This lexicon was found to be quite useful for the given work and effectively helps in determining opinion bearing words and their orientation or polarity but it was found that the resource quickly breaks down with terms from the socio-political domain. Even the frequent terms like 'treaty', 'pact', 'truce', 'agitation', 'mutiny', 'salvage', 'consensus', 'epidemics', 'brotherhood', 'bandh' etc. in the socio-political domain seem to be missing in the opinion lexicon. This motivated the author to develop a separate sentiment polarity lexicon comprising of prototypically positive and negative terms, specifically from the corpus. The lexicon development started with a small collection of 29 positive terms and 73 negative terms from the corpus. These terms were collected by a manual analysis of some random texts from the corpus. Further, consulting the online and available electronic resources like dictionaries, thesaurai and the WordNet, the list of terms was extended by adding some synonyms, inflected and derivational forms of the words. A sample of the developed Sentiment/Polarity Lexicon is presented in Table III. Such a collection allows having a rich lexicon of wider coverage comprising of both domain-specific terms from the corpus and domain independent terms from online resources. Currently, the Sentiment/Polarity terms contains about 300 positive terms and 800 negative terms. The given task of opinion and argument analysis in opinionated texts involves analyzing the opinions in the lexical and phrase levels first and then assigning an opinion label - Positive or Negative or Neutral to each statement/sentence. To illustrate the use of the Sentiment/Polarity Lexicon in the process of opinion analysis in the lower levels (lexical and phrase) and the assignment of opinion label in the sentence level, an excerpt of the real text from the corpus and its corresponding opinion analysis is presented in Fig. 1.
TABLE III. SAMPLE OF THE SENTIMENT/POLARITY LEXICON

\begin{tabular}{|c|c|}
\hline Positive & Negative \\
\hline $\begin{array}{l}\text { right : proper, correct, ok, okay } \\
\text { reform } \text { : reforms, reformed }\end{array}$ & $\begin{array}{l}\text { sack: fire, throw } \\
\text { insubordinate: insubordination }\end{array}$ \\
\hline $\begin{array}{l}\text { democracy: democratic, } \\
\text { democratized }\end{array}$ & $\begin{array}{l}\text { defy: disobey, defiance } \\
\text { unilateral: unilaterally }\end{array}$ \\
\hline $\begin{array}{l}\text { contribute: } \\
\text { contribution }\end{array}$ & $\begin{array}{l}\text { withdraw: } \quad \text { withdrew, } \\
\text { withdrawal }\end{array}$ \\
\hline hope: hopeful, hoping & hate: hated, hatred \\
\hline $\begin{array}{l}\text { thank: grateful, gratitude, } \\
\text { thankful }\end{array}$ & damage: damaging, damaged \\
\hline $\begin{array}{l}\text { respect: honor, dignity, } \\
\text { diginified, respectful }\end{array}$ & $\begin{array}{l}\text { contradict: contradiction, } \\
\text { contradicting insurgent: } \\
\text { insurgency }\end{array}$ \\
\hline $\begin{array}{l}\text { integrate: unite, unity, united, } \\
\text { integrated, integration, merge }\end{array}$ & refuse: refusal, denial \\
\hline salve: salvage, save & \\
\hline glory: glorious, famous & \\
\hline
\end{tabular}

For ease of illustration, the text is segmented in the sentence level and also analyzed for opinions in the lexical and phrase levels. While opinion phrases are annotated in XML like tagging notation, the opinion words/expressions have been underlined.

\# TITLE@ Maoists' double standard
\# DATE@2007 May 05
\#URL@ @ttp://ekantipur.com/the-kathmandu-
post/2007/05/05/editorial/maoists-double-
$\underline{\text { standard/108572.html }}$

1. A report of the UN Office of the High Commissioner for Human Rights in Nepal (OHCHR-Nepal), issued last week, manifests the $<$ neg $>$ glaring facts $</$ neg $>$ about the CPN-Maoist. \{Overall orientation: Negative\}

2. In the report the OHCHR-Nepal has starkly said that the Maoist cadres <neg>aren't complying $</$ neg $>$ with their party's commitments and <neg $>$ are not respecting $</$ neg $>$ the rights of the Internally Displaced Persons (IDPs) to voluntarily and safely return home. \{Overall orientation: Negative\}

Fig. 1. Excerpt of the analyzed text from the corpus for opinion orientation 


\section{B. Intensifier/Pre-modifier Lexicon}

For the task of analyzing the opinions and arguments in opinionated texts, besides determining the subjectivity (whether a given expression is an opinion or not) and detection of the orientation or polarity of opinions, it is also necessary to assess the strength or degree or intensity of opinions. Adjectives and adverbs have a significant role in the determination of the strength or degree of opinions as they necessarily change the intensity or degree of opinions being expressed [17-20]. Although, there can be finer grades of any opinion, we have limited the grading to seven broad scales "Lowest", "Lower", "Low", “Average", "High", "Higher" and "Highest" for our task. This correspond to a scale within the range -3 to 3 , where the mapping of the degrees to numeric values are as follows:

\section{Lowest $=-3 ;$ Lower $=-2 ;$ Low $=-1 ;$ Average $=0$, High $=1$; Higher $=2$, Highest $=3$}

The mapping above is partly guided by the three degrees of adjectives in English, viz., positive, comparative and superlative.In our case, positive degree refers to "Low", comparative degree to "Average" and superlative to "High". These three scales have been considered as our base strength categories. The remaining four scales "Lower" and "Lowest" and "Higher" and "Highest", respectively on the "Low" and "High" sides are produced as a result of the possible occurrence of intensifiers and pre-modifiers in front of the three major degrees of adjectives - "Low", "Average" and "High". Below, a few examples of the three degrees of adjectives from the corpus have been provided:

\section{high, low, good, bad, few, $\quad$ positive degree (“Low”) wealthy, powerful, successful: \\ higher, lower, better, worse, fewer, wealthier, more powerful, more successful: highest, lowest, best, worst, \\ comparative degree ("Average") \\ superlative degree ("High")} fewest, wealthiest, most powerful, most successful:

In addition to adjectives, the given work also considers intensifiers and pre-modifiers for the determination of the different degrees of strength of opinions. Intensifiers are essentially adverbs which are reported to have three different functions - emphasis, amplification and downtoning. Premodifiers, on the other hand, come in front of adverbs and adjectives. Both intensifiers and pre-modifiers play a role in conveying a greater and/or lesser emphasis to do something. A sample of the intensifier lexicon is presented in Table IV below:
TABLE IV. SAMPLE OF THE INTENSIFIER LEXICON

\begin{tabular}{|l|l|l|}
\hline Type & Value truly, & $\begin{array}{l}\text { Occurrences from the } \\
\text { Corpus }\end{array}$ \\
\hline Emphasizer & $\begin{array}{l}\text { Really: is really a good } \\
\text { genuinely, actually } \\
\text { idea. } \\
\text { Simply: merely, just, } \\
\text { only, plainly } \\
\text { Literally } \\
\text { For sure: surely, cannot say. } \\
\text { certainly, sure, for } \\
\text { certain, sure enough, } \\
\text { undoubtedly } \\
\text { Of course: naturally } \\
\text { I would literally trust } \\
\text { his judgments over } \\
\text { mine. } \\
\text { All we can say for } \\
\text { sure at this point is ... } \\
\text { There were many } \\
\text { tactical and strategic } \\
\text { compromises along the } \\
\text { way, of course. }\end{array}$ \\
\hline $\begin{array}{l}\text { Completely: all, } \\
\text { altogether, entirely, } \\
\text { totally, whole, wholly. } \\
\text { Absolutely: totally, } \\
\text { definitely, without } \\
\text { question, perfectly, } \\
\text { utterly. } \\
\text { Heartily: cordially, } \\
\text { warmly, with gusto } \\
\text { and without } \\
\text { reservation. }\end{array}$ & $\begin{array}{l}\text { Men and women are } \\
\text { completely equal in } \\
\text { value and dignity. } \\
\text { Ijust told them that we } \\
\text { should be absolutely } \\
\text { quiet. } \\
\text { Heartily approve of } \\
\text { socialism. }\end{array}$ \\
$\begin{array}{l}\text { Kind of: sort of, } \\
\text { kinda, rather, to some } \\
\text { extent, almost, all but } \\
\text { Mildly: gently }\end{array}$ & $\begin{array}{l}\text { The opponents were } \\
\text { kind of satisfied with } \\
\text { the answers of the } \\
\text { Prime Minister. } \\
\text { The Prime Minister } \\
\text { mildly protested the } \\
\text { proposal. }\end{array}$ \\
\hline
\end{tabular}

Below, the role of each category of intensifiers in terms of modifying the strength of opinions in example texts from the corpus is discussed:

"The loss of the Corby bi-election is a really significant watershed".

The intensifier "really" emphasizes the adjective "significant", thus increasing its intensity or degree to one level further up. In this respect, since the adjective "significant" represents the positive or "Low" degree, the intensifier "really" modifies the intensity of strength of the adjective to "Average".

"The electoral Commission was absolutely right to announce a review of the debacle".

Similarly, the intensifier "absolutely" amplifies the adverb "right", thus increasing its intensity or degree to the highest level. In this respect, the intensifier "absolutely" modifies the intensity of the strength of the adverb to "Highest". 
"Admittedly, this sounds rather disconcerting."

Likewise, the intensifier "rather" downtones the adverb "disconcerting" to one level down, thus modifying the intensity of the strength of the adverb to "Lower". Similarly, in Table V, a sample of the pre-modifiers lexicon is presented and the contribution of the pre-modifiers to the overall strengths of the opinion expressions is shown.

TABLE V. SAMPLE OF THE PRE-MODIFIERS LEXICON

\begin{tabular}{|c|c|c|}
\hline $\begin{array}{l}\text { Adverb/Adjective } \\
\text { (Initial strength) }\end{array}$ & Pre-modifier & Modified strength \\
\hline Fast (Low) & Very & Very fast (High) \\
\hline Careful (Low) & Lot more & Lot more careful (High) \\
\hline \multirow[t]{3}{*}{$\begin{array}{c}\text { Better (Average) } \\
\text { Serious (Low) }\end{array}$} & Much & Much better (High) \\
\hline & & $\begin{array}{l}\text { Much much better } \\
\text { (Higher) }\end{array}$ \\
\hline & & $\begin{array}{l}\text { Much more serious } \\
\text { (Higher) }\end{array}$ \\
\hline \multirow[t]{2}{*}{ Good (Low) } & Somewhat & $\begin{array}{c}\text { Somewhat good } \\
\text { (Average) }\end{array}$ \\
\hline & Quite & Quite good (Average) \\
\hline
\end{tabular}

\section{Report and Modal Verbs Lexicon}

For the task of determining the strength of opinions and arguments in opinionated texts, it is also necessary to analyze the intent or commitment level of the statement under consideration with respect to some thesis statement. One way of doing this is by looking at the choice of report or modal verbs used in the respective statements.

The higher the degree of assertiveness a modal/reporting verb represents, the stronger the commitment or intent level of the statement would be. In Table VI, a sample of the modal verb lexicon is presented and the role of modal verbs in commitment or intent level determination is illustrated.

TABLE VI. SAMPLE OF THE MOdAL VERBS LeXICON

\begin{tabular}{|c|c|c|}
\hline Type & Verb & $\begin{array}{l}\text { Strength } \\
\text { effects }\end{array}$ \\
\hline Ability/Possibility & Can & Average \\
\hline Ability/Possibility & Could & Low \\
\hline Permission & May & Average \\
\hline Permission & Might & Low \\
\hline Advice/Recommendation/Suggestion & Should & Average \\
\hline Necessity/Obligation & $\begin{array}{c}\text { Must, } \\
\text { Have to }\end{array}$ & High \\
\hline
\end{tabular}

Similarly, in Table VII, we present a sample of the Report Verb Lexicon.
TABLE VII. SAMPLE OF THE REPORT VERBS LEXICON

\begin{tabular}{|c|c|c|c|}
\hline Type & Low & Average & High \\
\hline Agreement & $\begin{array}{l}\text { admits, } \\
\text { concedes }\end{array}$ & $\begin{array}{c}\text { accepts, } \\
\text { acknowledges, } \\
\text { agrees }\end{array}$ & Agreement \\
\hline $\begin{array}{c}\text { Argument and } \\
\text { persuasion }\end{array}$ & Apologizes & $\begin{array}{c}\text { assures, } \\
\text { encourages, } \\
\text { interprets, } \\
\text { justifies, } \\
\text { reasons }\end{array}$ & $\begin{array}{l}\text { Argument and } \\
\text { persuasion }\end{array}$ \\
\hline Believing & $\begin{array}{l}\text { guesses, } \\
\text { hopes, } \\
\text { imagines }\end{array}$ & $\begin{array}{l}\text { believes, } \\
\text { claims, } \\
\text { declares, } \\
\text { expresses }\end{array}$ & Believing \\
\hline $\begin{array}{c}\text { Disagreement } \\
\text { and } \\
\text { questioning }\end{array}$ & $\begin{array}{l}\text { doubts, } \\
\text { questions }\end{array}$ & $\begin{array}{l}\text { challenges, } \\
\text { debates, } \\
\text { disagrees, } \\
\text { questions }\end{array}$ & $\begin{array}{c}\text { Disagreement } \\
\text { and } \\
\text { questioning }\end{array}$ \\
\hline Presentation & Confuses & $\begin{array}{c}\text { comments, } \\
\text { defines, reports, } \\
\text { states }\end{array}$ & Presentation \\
\hline Suggestion & $\begin{array}{l}\text { alleges, } \\
\text { intimates, } \\
\text { speculates }\end{array}$ & $\begin{array}{c}\text { advises, } \\
\text { advocates, } \\
\text { posits, suggests }\end{array}$ & $\begin{array}{l}\text { recommends, } \\
\text { urges }\end{array}$ \\
\hline
\end{tabular}

Source:[http://www.adelaide.edu.au/writingcentre/learning_guides /learningGuide_reportingVerbs.pdf]

To illustrate the use of the Intensifiers and Pre-modifiers Lexicon as well as the Report and Modal Verbs Lexicon for determining the commitment or intent level of the statements, an excerpt of real text from the corpus and its corresponding analysis is presented in Fig.2. below:

\footnotetext{
Along with the laundry list of domestic grievances

<commitment_level="Average" $>$ expressed $</$ commitment_level $>$ by Egyptian protesters

<commitment_level="High" $>$ calling $</$ commitment_level $>$ for an end to the regime of Hosni Mubarak, the popular perception of Egypt's foreign policy has also been a focal point of the demonstrations.\{Overall commitment level: "High"\}
}

Fig. 2. Excerpt of the analyzed text from the corpus for commitment level

For the determination of the overall commitment level and the opinion strength in the sentence level, the highest values available within the sentence for each of these two attributes has been taken.

\section{Discourse Markers and Rhetorical Relations Lexicon}

For analyzing the opinions and arguments in the sentence and higher levels, the rhetorical or discourse or coherence relations needs to be determined. These relations are crucial in establishing relationships between passages of text. 
Discourse markers can serve as effective sign posts to signal the presence of discourse or coherence or rhetorical relations in any discourse [21,22]. In Table VIII, a sample of the Discourse Markers and Rhetorical Relations Lexicon is presented.

TABLE VIII. SAMPLE OF THE RHETORICAL RELATIONS AND DISCOURSE MARKERS LEXICON

\begin{tabular}{|l|l|}
\hline Rhetorical relations & Discourse Markers \\
\hline Elaboration & $\begin{array}{l}\text { after, before, first, all the while, } \\
\text { in the past, .. }\end{array}$ \\
\hline Result & $\begin{array}{l}\text { briefly, hence, overall, thus, in } \\
\text { brief, to end,.. }\end{array}$ \\
\hline Reinforcement & $\begin{array}{l}\text { again, also, too, in addition, } \\
\text { above all, most of all, .. }\end{array}$ \\
\hline Contrast & $\begin{array}{l}\text { against, instead, rather, still, } \\
\text { versus, yet, even so,... }\end{array}$ \\
\hline Cause - Effect & $\begin{array}{l}\text { hence, since, therefore, thus, } \\
\text { whenever, as a result, .. }\end{array}$ \\
\hline Exemplification & $\begin{array}{l}\text { indeed, namely, for example, in } \\
\text { effect, such as, .. }\end{array}$ \\
\hline Conditional & $\begin{array}{l}\text { else, if, otherwise, unless, until, } \\
\text { while, as long as, ... }\end{array}$ \\
\hline
\end{tabular}

Source:[http://learning.londonmet.ac.uk/TLTC/connorj/Wri tingGroups/Writing/5\%20discourse\%20markers-signposts.pdf]

To illustrate the use of the Discourse Marker and Rhetorical Relations Lexicon in analyzing the discourse or coherence or rhetorical relations between supporting statements in texts, an excerpt of real text from the corpus and its corresponding analysis is presented in Fig.3. below. The text fragments having the discourse markers have been underlined in the figure.

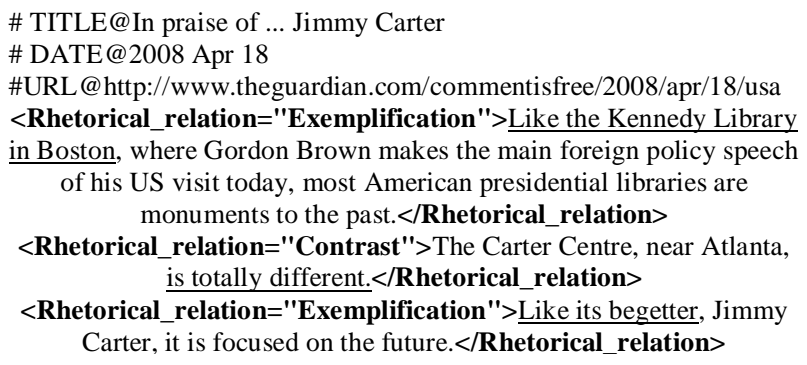

Fig. 3. Excerpt of the analyzed text from the corpus for rhetorical relations

\section{Development Of An Automatic Annotation Tool And Evaluation Of Performance}

Based on the linguistic resources described in the previous section, an automatic annotation tool has been developed, which segments the text into paragraphs and sentences, then annotates the text for opinions and arguments with the attributes of the semantic tagset. For the evaluation of the performance of the annotation tool, 500 texts have been randomly taken from the 10,000 automatically annotated texts by the tool. The accuracy of the performance of the tool was evaluated manually in terms of annotations by the machine compared to what a human would have annotated for the same. Since the annotation tool highly relies on the linguistic resources developed in terms of annotation, a comparative analysis of the use of the baseline linguistic resource (opinion lexicon by [12]) versus our extended linguistic resource (sentiment/polarity lexicon by [12]augmented with domain specific opinion terms and patterns) for the same 200 texts mentioned above was carried out. The accuracy of the performance of the automatic tagger application in terms of tagging was calculated as follows:

$$
\begin{aligned}
& \text { Accuracy }=\text { tag } / T \\
& \text { Where } T=\text { Total number of tagged sentences } \\
& \text { tag }=\text { Total number of correctly tagged sentences }
\end{aligned}
$$

The accuracy scores for the different annotation tasks are presented in Table IX below:

TABLE IX. ACCURACY SCORES FOR THE DIFFERENT TAGGING TASKS

\begin{tabular}{|l|l|l|}
\hline S.No. & Annotation task & Accuracy (\%) \\
\hline 1 & Opinion orientation & $61.5 \%$ \\
\hline 2 & Opinion strength & $63.75 \%$ \\
\hline 3 & Commitment or intent level & $72.5 \%$ \\
\hline 4 & Rhetorical relations & $47.5 \%$ \\
\hline
\end{tabular}

Similarly, in Table X, the accuracies of the annotation tool for the attribute 'opinion orientation' using the baseline resource and our extended linguistic resource are presented.

\begin{tabular}{|c|c|c|}
\hline S.No. & $\begin{array}{lcc}\text { Annotation } & \text { Task } & \text { (Opinion } \\
\text { Orientation) } & \text { versus } & \text { Linguistic } \\
\text { Resources } & & \end{array}$ & Accuracy (\%) \\
\hline 1 & Baseline Linguistic Resource & $55 \%$ \\
\hline 2 & Extended Linguistic Resource & $68 \%$ \\
\hline
\end{tabular}

TABLE X. ACCURACY SCORES FOR BASELINE AND EXTENDED LINGUISTIC RESOURCES

The accuracy scores in Table IX show that the annotation tasks have achieved reasonably good results. The scores for each of these individual tasks are expected to further improve as the linguistic resources are further enhanced in terms of coverage and size. The task currently performing the least is the determining the rhetorical relations. This is partly because implicit discourse markers in texts, which also potentially act as signposts for denoting the presence of rhetorical relations in between statements, have not been considered at the moment. The performance of the tool for this particular task is expected to further improve as some special tailored rules designed to address such situations are developed.

Similarly, the accuracy scores in Table X show that the performance of the tool using the extended linguistic resource is better than using the baseline linguistic resource. This is understandable as the extended linguistic resource has a rich collection of domain specific terms from the corpus in addition to the opinionated terms from the baseline linguistic resource. The accuracy scores of the tool using the extended linguistic resources is expected to improve further as more of such domain specific terms and patterns are gathered.

\section{CONCLUSION AND FUTURE WORKS}

The paper presented on the ongoing efforts towards developing linguistic resources for automatic annotation and consequently analysis of opinions and arguments in editorials 
and op-eds. An automatic annotation tool developed for this purpose was reported to be performing with reasonably good accuracies. Currently, the annotation tool basically relies heavily on the linguistic resources and some contextual rules to annotate the texts for opinions and arguments. In due course of time, some machine learning capabilities are being planned to incorporate to the tool so that the same task can be handled more accurately and in a larger scale. There are also plans to work on building a synthesis of opinions and arguments on a particular topic from multiple editorial sources. Such a synthesis helps to get more or less a true picture of the events and at the same time also potentially reveal the inherent biases and prejudices. At the moment, works are underway for developing a framework for creating such a synthesis.

\section{ACKNOWLEDGMENT}

I would like to extend my sincere thanks to the University Grants Commission, Nepal for supporting this work. My sincere thanks also go to my Research students, Mr. Chandan Prasad Gupta and Mr. Rohit Man Amatya at the Information and Language Processing Research Lab, Department of Computer Science and Engineering, Kathmandu University for their technical help for conducting this Research work. I would similarly like to thank my $\mathrm{PhD}$ advisors, Prof. Patrick SaintDizier from IRIT Labs, Toulouse, France and Prof. Patrick A.V. Hall, Kathmandu University for their continuous help and guidance to this work.

\section{REFERENCES}

[1] B.K. Bal, P. Saint-Dizier (2010). Towards Building Annotated Resources for Analyzing Opinions and Argumentation in News Editorials. LREC, Malta, ELRA.

[2] H. Stonecipher (1979). Editorial and Persuasive Writing:Opinion Functions of the News Media. New York: Communication Arts Books. Hastings House, Publishers.

[3] T. Van Dijk (14-17 December, 1995). Opinions and Ideologies in Editorials. Paper Symposium of Critical Discourse Analysis. Language, social life and critical thought. Athens.

[4] N. B. Wekesa (2012). Assessing Argumentativity in the English Medium Kenyan Newspaper Editorials from a Linguistic-Pragmatic Approach. International Journal of Humanities and Social Science , 2 (21), 133144.

[5] T. Wilson (2003). Annotating Opinions in World Press. Proceedings of the SIGdial-03, (pp. 13-22).

[6] T. Wilson (2005). Annotating Attributions and Private States. In Proceedings of the ACL 2005 Workshop: Frontiers in Corpus Annotation II: Pie in the Sky, (pp. 53-60).

[7] V. Stoyanov, C. Cardie, D. Litman, \& J. Wiebe (2004). Evaluating an Opinion Annotation Scheme Using a New Multi-Perspective Question and Answer Corpus. (Q. S. Wiebe, Ed.) Computing Attitude and Affect in Text: Theory and Practice, 77-89.

[8] J. Read, D. Hope, \& J. Carroll(2007). Annotating Expressions of Appraisal in English. Proceedings of the ACL 2007 Linguistic Annotation Workshop. Prague, Czech Republic.
[9] J. Martin, \& P. R. White (2005). The Language of Evaluation: Appraisal in English. London: Palgrave: Macmillan.

[10] L. Carlson, D. Marcu \& M. Okurowski (2001). Building a Discoursetagged Corpus in the Framework of Rhetorical Structure Theory. In Proceedings of the Second Sigdial Workshop on Discourse and Dialogue. 16, pp. 1-10. Aaolborg, Denmark: Annual Meeting of the ACL, Association for Computational Linguistics, Morristown, NJ.

[11] M.Taboada, \& J. Renkema (2008). http://www.sfu.ca/rst/06tools/discourse_relations_corpus.html. Retrieved August 18, 2013, from http://www.sfu.ca.

[12] M. Hu \& B. Liu (2004). Mining and Summarizing Customer Reviews. Proceedings of the ACM SIGKDD International Conference on Knowledge Discovery and Data Mining (KDD-2004), Aug 22-25, 2004. Seattle, Washington, USA.

[13] B. Liu, M. Hu \& J. Cheng (2005). Opinion Observer: Analyzing and Comparing Opinions on the Web. Proceedings of the 14'th International World Wide Web Conference (WWW-2005), May 10-14, 2005. Chiba, Japan.

[14] E. Riloff, J. Wiebe, \& T. Wilson(2003). Learning Subjective Nouns Using Extraction Pattern Bootstrapping. In Proceedings of the Seventh Conference on Natural Language Learning at HLT-NAACL 2003Volume 4 (CONLL '03). 4, pp. 25-32. Stroudsburg, PA, USA: Association for Computational Linguistics.

[15] T. Wilson \& J.M.Wiebe. (2005). Recognizing contextual polarity in phrase-level sentiment analysis. Conference on Human Language Technology and Empirical Methods in Natural Language Processing, (pp. 347-354).

[16] A. Esuli, \& F. Sebastiani (2006). SENTIWORDNET: A Publicly Available Lexical Resource for Opinion Mining. In Proceedings of the 5 'th Conference on Language Resources and Evaluation (LREC '06), (pp. 417-422).

[17] V. Hatzivassiloglou \& K. R. McKeown (1997). Predicting the semantic orientation of adjectives. In Proceedings of the Eigth Conference on European Chapter of the Association for Computational Linguistics (EACL '97) (pp. 174-181). Stroudsburg, PA, USA: Association for Computational Linguistics.

[18] V. Hatzivassiloglou \& J. M. Wiebe (2000). Effects of Adjective Orientation and Gradability on Sentence Subjectivity. In Proceedings of the 18'th Conference on Computational Linguistics (COLING '00). 1, pp. 299-305. Stroudsburg, PA, USA: Association for Computational Linguistics.

[19] P. Chesley, B. Vincent, L. Xu, \& R. Srihari (2006). Using Verbs and Adjectives to Automatically Classify Blog Sentiment. In Proceedings of AAAI-CAAW-06, the Spring Symposia on Computational Approaches to Analyzing Weblogs.

[20] F. Benmara, C. Cesarano, A. Picariello, D. Reforgiato, \& V. Subrahmanian (2007). Sentiment Analysis: Adjectives and Adverbs are Better than Adjectives Alone. Proceedings of the International Conference on Weblogs and Social Media (ICWSM).

[21] D. Marcu (1998). A Surface-based Approach for Identifying Discourse Markers and Elementary Textual Units in Unrestricted Texts. In S. Manfred, L. Wanner, \& E. Hovy (Ed.), Proceedings of COLING-ACL Workshop on Discourse Relations and Discourse Markers, (pp. 1-7). Montreal, Canada.

[22] B. Fraser (1999). What are discourse markers? Journal of Pragmatics (31), 931-952. 